John Carroll University

Carroll Collected

2020

Opposites attract: Impact of background color on effectiveness of emotional charity appeals

Choi Jungsil

Yexin Jessica Li

Priyamvadha Rangan

Bingqin Yin

Surendra N. Singh

Follow this and additional works at: https://collected.jcu.edu/fac_bib_2020

Part of the Marketing Commons, and the Operations and Supply Chain Management Commons 


\section{Opposites attract: Impact of background color on effectiveness of emotional charity appeals $\boldsymbol{\Sigma}^{2}$}

Keywords:

Donations

Color psychology

Prosocial behavior

Charity appeals

Emotions
The present work utilizes research on context effects and color psychology to investigate how background color can enhance the effectiveness of positive and negative charity appeals. Five experiments measuring both actual donations and donation intention examine the hypothesis that a negative charity appeal against an orange (vs. blue) background and a positive charity appeal against a blue (vs. orange) background will increase donations. We propose that this is because blue and orange colors are incongruous with positive and negative charity appeals, respectively, due to the affective valences of the appeals and the perceptions of warmth and coldness cued by the background colors. This incongruity enhances the attention people pay to the charity appeals, thereby strengthening their emotional response to the appeals, which increases charitable donations. When attention is manipulated, people who pay a high (vs. low) level of attention to the charity appeal are more likely to donate regardless of the color and valence of the appeal, suggesting attention is an important antecedent to the intensity of the emotional response and subsequent donation behavior. We also identify affect diagnosticity as a boundary condition for the effect - when people are informed that color affects their emotions, the contextual effect of color disappears.

\section{Introduction}

There are over 1.5 million nonprofit organizations in the United States (National Center for Charitable Statistics, 2017) that cumulatively raised $\$ 390$ billion in 2016 , with $72 \%$ of the contributions coming from individual donors (Giving USA Foundation, 2017). The demand for help from nonprofits is growing (White \& Peloza, 2009), making it increasingly important for these organizations to enhance the effectiveness of their donation requests. At the same time, consumers are ex- 
posed to far greater amounts of information than ever before. For example, adults in the United States spent $10 \mathrm{~h}$ and $54 \mathrm{~min}$ a day processing information across various media platforms (digital, audio and television) in the second quarter of 2017 (Nielsen Company, 2017). In today's image-laden, visually evocative media environment, it is critical for nonprofit marketers to identify novel and effective ways to attract potential donors. We posit that the strategic use of background color in emotional charity appeals will help marketers achieve this goal by enhancing potential donors' attention to the appeals and bolstering donation behavior.

Although color is ubiquitous and fundamental to human perception, and color choice an ever-present consideration in advertising, "little academic research has investigated the role that color plays in marketing" (Labrecque \& Milne, 2012, p. 711). Further, there is "limited research on the influence of color on consumer purchases" (Bagchi \& Cheema, 2013, p. 948). Importantly, different colors are shown to evoke distinct positive or negative emotional responses in the viewer (e.g., Karp \& Karp, 2001; Palmer, Schloss, Xu, \& Prado-León, 2013). We contend that when charity appeals whose messages (i.e., text and images) evoke either positive or negative emotions are displayed against colored backgrounds that also trigger positive or negative emotions, congruent or incongruent effects will occur. This will either enhance or mitigate the emotional responses to these appeals, thereby influencing donation behavior.

Across five studies, we explore whether people pay variable attention to emotional charity appeals depending on whether they are combined with colored backgrounds that are emotionally congruent or incongruent with the appeal, and determine whether this differential processing of the visual stimuli has any impact on donation behavior in both lab and field settings. Next, we investigate whether attention enhances emotional responses to the charity appeal, and whether this, in turn, increases donation behavior. Further, we investigate the hypothesized attention-driven mechanism by directly manipulating attention level, and examine whether people in a high (vs. low) attention level are more likely to donate by responding to emotional appeals regardless of the joint effect of colors and charity appeals. Lastly, we explore whether the impact of emotions on donation decision making holds when potential donors are made aware of the source of their affect.

This research has both theoretical and practical implications. In today's visually laden media environment, it is critical for ads to cut through the clutter and gain consumers' attention. This research identifies a novel mechanism by which nonprofit marketers can direct visual attention to their donation appeals, optimize the persuasiveness of their message and enhance their fundraising effectiveness. The results further our understanding of visual cues and their interaction with emotional content, and contribute to research on color psychology and the broader charitable giving literature.

\section{Theoretical background}

\subsection{Charity appeals, emotions, and helping behavior}

Charity appeals are often crafted with the distinct goal of influencing viewers' emotions (Isen \& Noonberg, 1979; Small \& Verrochi, 2009; Thornton, Kirchner, \& Jacobs, 1991). Both positive and negative emotions increase benevolence when compared to a neutral emotional state, with stronger emotions generally eliciting stronger helping responses (Cialdini, Baumann, \& Kenrick, 1981; Krebs, 1970). Negative appeals, such as those featuring a crying child and a heart-wrenching story, can increase donations by eliciting strong negative emotions in the viewer (Bagozzi \& Moore, 1994; Small \& Verrochi, 2009). An abundance of literature finds that negative emotions increase helping behavior, either because the observer wishes to improve the welfare of others (altruistic motivation) or to relieve one's own intense feelings of sadness (egoistic motivation) (Batson, Duncan, Ackerman, Buckley, \& Birch, 1981; Cialdini, Darby, \& Vincent, 1973). For example, Cialdini et al. (1987) found that enhancing feelings of sadness in an observer leads to an increase in helping behavior due to the observer's egoistic desire to relieve his or her negative affective state. Work by Batson et al. (1989) suggests that sadness increases helping behavior in the observer because it engenders the altruistic goal of relieving another's distress.

In contrast, positive charity appeals increase helping behavior by evoking positive emotions in the viewer (Cunningham, Steinberg, \& Grev, 1980). Positive charity appeals typically showcase happy faces and hopeful, heartfelt messages (e.g., an ad for the Red Cross featuring a picture of a smiling child along with an uplifting statement, "your donation brings hope.") Positive emotions may increase donation behavior for several reasons. The mood-maintenance hypothesis suggests that people engage in prosocial behavior because they are motivated to maintain their levels of elevated affect (Clark \& Isen, 1982; Isen \& Levin, 1972) whereas the concomitance hypothesis states that positive emotions influence helping indirectly through other processes, such as an increased liking of others and greater feelings of optimism and control (Cialdini, Kenrick, \& Baumann, 1982; Manucia, Baumann, \& Cialdini, 1984).

Both positive and negative emotions increase helping behavior and the focus of this research is not to compare their relative effectiveness. Rather, our objective is to examine whether adding a contextual cue to an emotional appeal can increase attention and the intensity of the experienced emotion. Disparate images have been used as contextual cues in charity appeals to enhance emotions and promote prosocial behavior (Grinstein, Hagtvedt, \& Kronrod, 2019). Specifically, when the visual portion of a charity (print) appeal simultaneously features an image of a visually appealing entity (person or object) against the backdrop of a displeasing visual of a group of entities, the visual cues enhance both empathy and the resultant prosocial behavior.

Since both positive and negative emotions elicited by a charity appeal lead to greater helping behavior and persuasion effectiveness, enhancing emotions of either positive or negative valence should lead to a rise in the resulting donations. In the next section, we discuss a visual contextual cue that can enhance the emotions elicited by positive and negative appeals. 


\subsection{Color-emotion associations and schema incongruity}

Colors are a critical component of visual perception. Research in consumer behavior has uncovered important ways in which colors can influence attention, cognition, motivation and behavior (Bagchi \& Cheema, 2013; Gorn, Chattopadhyay, Sengupta, \& Tripathi, 2004; Labrecque, Patrick, \& Milne, 2013). For instance, color (vs. black-and-white) induces people to pay attention to concrete (vs. abstract) aspects of the stimulus due to its association with low-level construal (Lee, Deng, Unnava, \& Fujita, 2014). In addition, consumers deduce better product quality from a color (vs. black-and-white) ad when they are not motivated to process the ad. But, when highly motivated to process the ad, consumers will rate the advertised product less favorably in the color (vs. black-and-white) condition, if processing the ad claims is resource-demanding (Meyers-Levy \& Peracchio, 1995). Research on discrete colors shows that they influence motivation differently depending on the context. Red activates aggression in a competition context (Bagchi \& Cheema, 2013), approach motivation in a relational context (Elliot \& Niesta, 2008), and avoidance motivation in a performance context (Elliot, Maier, Moller, Friedman, \& Meinhardt, 2007; Mehta \& Zhu, 2009) due to the learned association between a color and its meaning in the particular context.

Previous studies also show that different colors are cognitively linked to different emotions (e.g., Karp \& Karp, 2001; McMenamin et al., 2013; Palmer et al., 2013). One study showed that, out of 37 colors, orange is most highly correlated with the concept of happiness (Palmer et al., 2013), while another study by the same authors found that orange is more likely to be associated with happy faces than with neutral or sad ones. Moreover, in an investigation of whether colors serve as a diagnostic feature for discriminating emotional and non-emotional objects, positively-valenced images were shown to contain more "reddishyellow" (i.e., orange) hues than non-emotional images (McMenamin et al., 2013).

In contrast, evidence points to a strong link between the color blue and sadness. Blue is one of the lowest-rated colors on the emotion-pleasure scale (happy, satisfied, cheerful, hopeful, and surprised) (Schifferstein \& Tanudjaja, 2004), and blue-violet is equated with sadness in participants' color profiles of mood states (Levy, 1984). Fourth graders who were presented with a list of emotions and asked to write down the first color that comes to mind when the emotion is given indicated that blue is most often associated with sadness (Karp \& Karp, 2001). The association between color and emotion can also be found in pop culture references, such as the 2015 movie "Inside Out," in which blue represents sadness. As a result, we propose that a positive charity appeal is congruent with the color orange and a negative charity appeal is congruent with the color blue.

Additionally, different colors are associated with different perceptions of physical temperature. The conventional associations in a culture link some colors to cooling sensations and others to warming sensations. In general, colors like red and orange are perceived to be extremely warm and blue is perceived to be the least warm (Fenko, Hendrik, \& Schifferstein, 2010). Orange is rated warmest and blue coldest in a semantic association task (Sivik \& Taft, 1989). As such, strong correlations exist between perceived warmth and visual exposure to warm colors (e.g., orange) and perceived coldness and visual exposure to cool colors (e.g., blue). Further, researchers have uncovered a relationship between temperature perceptions and affective states, with negative affective states (e.g., stress, anxiety, etc.) lowering perceptions of temperature, and positive affective states (e.g., relaxation, security, etc.) raising it (Boudewyns, 1976; Crawford, Friesen, \& Tomlinson-Keasey, 1977).

Based on the aforementioned research, we suggest that a congruency exists in terms of emotional valence and color. Specifically, we expect that a negative charity appeal that induces negative emotions will be more congruent with blue due to its associations with sadness and coldness, whereas a positive charity appeal will be more congruent with orange because of its association with warmth and happiness. A pilot test was conducted to test this hypothesis. One-hundred and three participants $\left(M_{\text {age }}=33.0\right.$ years; 62 males and 41 females) were recruited online for a 2 (color: blue, orange) $\times 2$ (appeal: positive, negative) experiment (see Supplementary material). Participants indicated the degree to which they perceived incongruity between the color and the appeal (i.e., "the message and picture in the ad did not match the background color of the ad," "something was odd about the design of the ad," strongly disagree (1)-strongly agree (7); $r=0.75, p<.001$ ). An ANOVA revealed a significant interaction of color and appeal type such that people saw the incongruent combinations as more incongruent than the congruent ones, $F(1,99)=8.36, p<.01$. That is, a positive appeal against a blue background was perceived to be more incongruent than a positive appeal against an orange background $\left(M_{\text {blue }}=3.64\right.$ vs. $M_{\text {orange }}=2.65 ; F(1,99)=4.32, p<.05$ ). Likewise, a negative appeal against an orange background was perceived to be more incongruent than a negative appeal against a blue background $\left(M_{\text {orange }}=4.13\right.$ vs. $\left.M_{\text {blue }}=3.15 ; F(1,99)=4.04, p<.05\right)$.

\subsection{Stimulus incongruence, attention and emotion}

People consider incongruent information to be more informative and give it more weight than congruent information (Crocker, Hannah, \& Weber, 1983; Fiske, Kinder, \& Larter, 1983). Advertisements that are incongruent with an elicited schema draw more attention because the unanticipated or unusual information motivates people to resolve the incongruence (Goodstein, 1993; Moore, Stammerjohan, \& Coulter, 2005). When information is congruent with expectations, people pay less attention to it and do not engage in deeper, conscious processing to conserve cognitive resources (Fiske et al., 1983; Machleit, Allen, \& Madden, 1993). We therefore expect people to pay more attention to an incongruent (vs. congruent) combination of charity appeal and color.

Past research suggests that emotions are elicited based upon a person's subjective appraisal of occurrences or objects in the surrounding environment, and that attention is necessary to evoke an emotional response to a stimulus (e.g., Okon-Singer, Tzelgov, \& Henik, 2007; Scherer, 1999; Vuilleumier, Armony, Driver, \& Dolan, 2003). Eimer, Holmes, and McGlone (2003) argue that the detection and processing of emotional information requires attention and show that when one's attention is drawn 
away from an emotion-laden stimulus, the stimulus-specific emotional effects are eliminated. Additionally, people under high and moderate attentional loads express low affective reactions (Pessoa, McKenna, Gutierrez, \& Ungerleider, 2002; Pessoa, Padmala, \& Morland, 2005), which indicates that emotional reactions are less likely to occur when people do not pay sufficient attention to the stimulus.

We posit that incongruence from an opposite-valenced contextual stimulus (i.e., negative appeal-orange background or positive appeal-blue background) will draw more attention, thereby intensifying affective responses to the positive or negative charity appeal and increasing prosocial behavior. This position is in accord with Mandler (1982), who suggests that emotional responses are intensified by somewhat incongruent conditions rather than congruent conditions. It also comports with findings demonstrating that strong positive and negative emotions increase advertising effectiveness and helping behavior (Burke \& Edell, 1989; Edell \& Burke, 1987; MacKenzie, Lutz, \& Belch, 1986). In sum, we predict a moderated serial mediation effect, such that charity appeal and color interact to increase donations by accentuating viewers' emotional responses through enhanced attention. We focus our investigation on two colors - orange and blue - that have been linked to positive and negative affect and warmth and coldness, respectively. ${ }^{1}$

Formally, we make the following hypotheses:

H1. A positive (negative) appeal with a blue (orange) background will elicit greater donations than a positive (negative) appeal with an orange (blue) background.

H2. The relationship between appeal-type and color on donations will be mediated by enhancement of (1) attention and (2) emotional intensity.

\subsection{Boundary condition}

Research suggests affect diagnosticity, or awareness that emotions are influenced by an external source, may be a boundary condition for our hypothesized effects (Di Muro \& Murray, 2012; Kim, Park, \& Schwarz, 2010; Schwarz \& Clore, 1983). The impact of excitement and peacefulness on product evaluations is erased when people are made aware that their mood is influenced by the mood-induction task they performed (Kim et al., 2010), and participants who are made aware that music affects their emotions no longer choose products based on the music they hear (Di Muro \& Murray, 2012). We thus propose that the effect of color on the effectiveness of charity appeals will be significantly reduced when people are made aware that their emotions may be influenced by color cues.

H3. Awareness that color can influence emotions will significantly reduce the effect of color on the effectiveness of charity appeals.

Five studies were conducted to test our hypotheses. Studies 1-1 (lab setting) and 1-2 (field study) measured how actual donation behavior was affected by the interaction of background color and appeal type. Study 2 investigated the mediating role of attention and emotions on the relationship between incongruency and donation intention. Study 3 experimentally manipulated attention, thereby strengthening the ability to infer causality from attention to donation (Pirlott \& MacKinnon, 2016). Finally, Study 4 examined whether the effect of incongruent background color on donation behavior disappears when people are made aware of the source of their emotions. In all studies (except study 1-2), people participated for monetary compensation. Participants were randomly assigned to various conditions, and the data were collected in the field, computer lab or Amazon's MTurk. In all studies, saturation and luminance (perceived brightness) were kept constant; the colors differed only in their hues. Charity appeals were adapted from actual advertisements for the following charities: Salvation Army, Save the Children and World Help. Exit interviews revealed that no participants guessed the true purpose of the studies.

\section{Study 1-1}

Study 1-1 was designed to test the central hypothesis that the effectiveness of positive and negative charity appeals on donation behavior depends on the background color of the charity advertisement (i.e., orange vs. blue). Specifically, we hypothesized that incongruent color-appeal combinations will lead to greater donations than congruent ones (H1).

\subsection{Participants and method}

Seventy-seven college students ( $M_{\mathrm{age}}=21.4$ years; 43 males, 34 females) from a large public university in the Midwest participated in the study. They were randomly assigned to conditions in a 2 (appeal: positive vs. negative) $\times 2$ (color: orange vs. blue) between-subjects design. Both positive and negative appeals were adapted from those used by Save the Children, a nonprofit that helps supply food, health care, and education to children in 120 countries (see Supplementary material).

\footnotetext{
${ }^{1}$ We choose to use orange instead of red because, although the latter color possesses longer wavelengths, it is also associated with schemas that are undesirable such as threat, anger, and aggression (Pryke, 2009). Further, orange has the added benefit of being an optimal contrast to blue, as they are opposing colors in well-established color models (Fehrman \& Fehrman, 2004).
} 


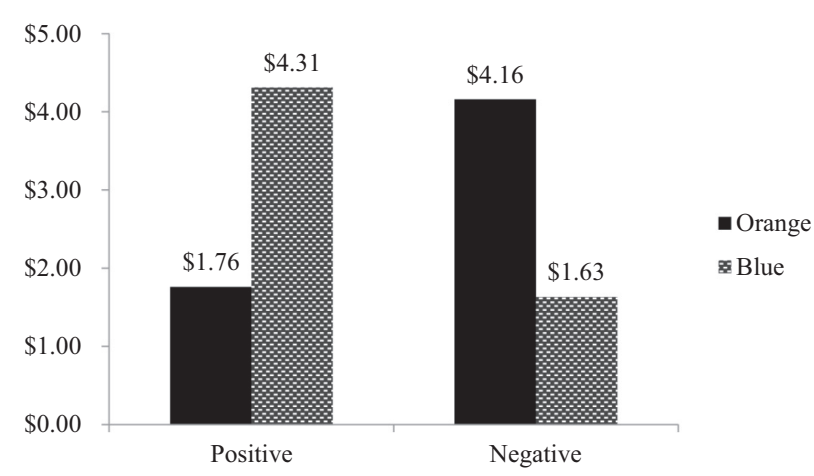

Fig. 1. Interaction of color and message on donation behavior (study 1-1).

A pretest confirmed that the appeals elicited the intended emotions (see Appendix A for details). In the main experiment, the positive and negative charity appeals were presented against an orange background (hue $=15$, saturation $=239$, luminance (perceived brightness) $=128$, transparency: $90 \%$ ) or a blue background (hue $=170$, saturation $=239$, luminance $=128$, transparency: $90 \%)^{2}$ Participants first completed an unrelated half-hour marketing survey, for which they expected to receive a $\$ 10$ payment. After completing that survey, they were presented with the charity advertisement on their computer screens. They answered a few questions about the charity, including their familiarity with the Save the Children organization $(1=$ "not at all familiar," 5 = "very familiar") because previous research shows familiarity with a brand or product is an important determinant of attitudes, behavioral intentions, and purchase likelihood (e.g., Laroche, Kim, \& Zhou, 1996). At the end of the study, participants were asked if they would like to donate any part of their payment $(\$ 0-\$ 10)$ to the charity, with the assurance that any contribution they made would be strictly voluntary and confidential. As they left the lab, participants received empty envelopes to place the money they pledged to the charity (this money was then donated to Save the Children).

\subsection{Results and discussion}

A 2 (appeal: positive vs. negative) $\times 2$ (color: orange vs. blue) between-subjects ANCOVA was conducted with donation amount as the dependent variable and charity familiarity as a covariate (exclusion of this covariate does not change any of the results). The analysis revealed a significant interaction of color and appeal $(F(1,72)=9.39, p<.01)$. Pairwise comparisons showed that people donated almost three times more money after reading the negative appeal against the orange background than the blue background ( $\$ 4.16$ vs. $\$ 1.76 ; F(1,72)=4.25, p<.05$ ). The effect was reversed for the positive appeal; donations were significantly higher for the blue background than the orange background ( $\$ 4.31$ vs. $\$ 1.63 ; F(1,72)=5.21, p<.05$ ) (Fig. 1). No main effects were found ( $p s>.1$, respectively). Familiarity with the organization did not have an impact on donation amount $(F(1$, $72)<1, p>.1)$.

The results of Study 1-1 show that incongruent appeals (i.e., negative appeal against an orange background/positive appeal against a blue background) are more effective at eliciting donations than congruent ones, which supports Hypothesis 1.

\section{Study 1-2}

Study 1-2 attempted to replicate the results of 1-1 in the field to enhance external validity. We partnered with the Salvation Army and launched a Back to School Supplies email campaign. The field study employed a 2 (appeal: positive vs. negative) $\times 2$ (colors: blue vs. orange) between-subjects design.

\subsection{Materials}

\subsubsection{Mailing list}

A mailing list with 10,528 people (out of a total county population of approximately 118,000 people) was acquired. The mailing list contained each person's name, email, address, age, and income. We first sorted the mailing list by income categories (below $\$ 50,000, \$ 50,001-\$ 74,999, \$ 75,000-\$ 99,999$, and above $\$ 100,000$ ). One-fourth of the participants were randomly selected from each income category and placed into one of the four charity appeal conditions. We used the same color system as study 1-1 (orange background: hue $=15$, saturation $=239$, luminance $=128$ and blue background: hue $=170$, saturation $=239$, luminance = 128). In each condition, 2632 people were randomly assigned to receive one of the four Back to School Supplies donation request email newsletters.

\footnotetext{
${ }^{2}$ We created different background colors using the HSL model (Hue, Saturation, and Luminance or Perceived Brightness) and Transparency, which are provided in the PowerPoint color system.
} 


\subsubsection{Donation request email newsletters' content}

Four versions of donation request email newsletters were created through an email marketing software-Constant Contact-to correspond to the four charity appeal conditions (see Supplementary material).

\subsubsection{Pretest}

A pretest was conducted to ensure that the ads elicited the intended emotions. The results showed that the positive ad was indeed rated more positive $(p<.001)$ and happy $(p<.001)$ than the negative ad. The negative ad was rated more negative $(p<.001)$ and sad $(p<.001)$ than the positive ad (see Appendix B).

\subsubsection{Pictures used in donation request email newsletter}

To enhance the positive and negative effects of the charity appeals, we purchased and incorporated stock images from an online vendor in the appeals.

\subsubsection{Online donation links and other donation options}

A "DONATE HERE" button was created with one of four distinct donation links that corresponded to the four appeal conditions. Interested donors could click on the button and be directed to the donation website. Donors could also choose to send a check to the Salvation Army at the address listed on each appeal.

\subsubsection{Campaign duration}

To increase response rate, five rounds of emails were sent to the same participants in each condition (July 18th, 2017-August 9th, 2017).

\subsubsection{Average donation per click}

Given the uniqueness of an email campaign, where feedback sometimes shows that an email was opened even if it wasn't (e.g., in Gmail, there is a function to mark all emails as read), we computed average donation by dividing the total donation amount by the number of clicks on the donation button for each condition.

\subsection{Results and discussion}

\subsubsection{Total donation amount}

We received a total of $\$ 775$. The negative-orange appeal generated the most donations ( $\$ 350$, range: $\$ 50$ to $\$ 100$ ), followed by the negative-blue appeal ( $\$ 175$, range: $\$ 25$ to $\$ 100)$, the positive-orange appeal ( $\$ 150$, range: $\$ 50$ to $\$ 100$ ) and finally the positive-blue appeal ( $\$ 100$, range: $\$ 25$ to $\$ 50)$.

\subsubsection{Average donation per click}

Results from a two-way (color $\times$ appeal) ANOVA showed a marginally significant interaction $(F(1,39)=3.01, p=.09$ ). Pairwise comparisons revealed that people who saw the negative-orange appeal donated significantly more than people who saw the negative-blue appeal $\left(M_{\text {negative+orange }}=\$ 50.00, M_{\text {negative }+ \text { blue }}=\$ 14.58, F(1,39)=7.16, p=.01\right)$. However, average donations between people who saw the positive-orange appeal and those who saw the positive-blue appeal did not differ $\left(M_{\text {positive }+ \text { orange }}=\right.$ $\left.10.71, M_{\text {positive+blue }}=\$ 10.00, F(1,39)<1\right)$. There was also a main effect of appeal type. Replicating previous research (e.g., Small $\&$ Verrochi, 2009), negative appeals elicited more donations than positive appeals $\left(M_{\text {negative }}=\$ 32.29, M_{\text {positive }}=\$ 10.36, F(1\right.$, $39)=4.81, p=.03$ ). Finally, results indicated a marginally significant main effect of background color; people donated more to the appeals against the orange background than the ones against blue background $\left(M_{\text {orange }}=\$ 30.36 M_{\text {blue }}=\$ 12.29, F(1,39)=\right.$ $3.27, p<.08$ ). (see Fig. 2).

The results of study 1-2 differ from those of 1-1 and provide only partial support for Hypothesis 1 . In study 1-1, we used charity appeals from international nonprofit organizations that showed children in need from underdeveloped countries. Victims in

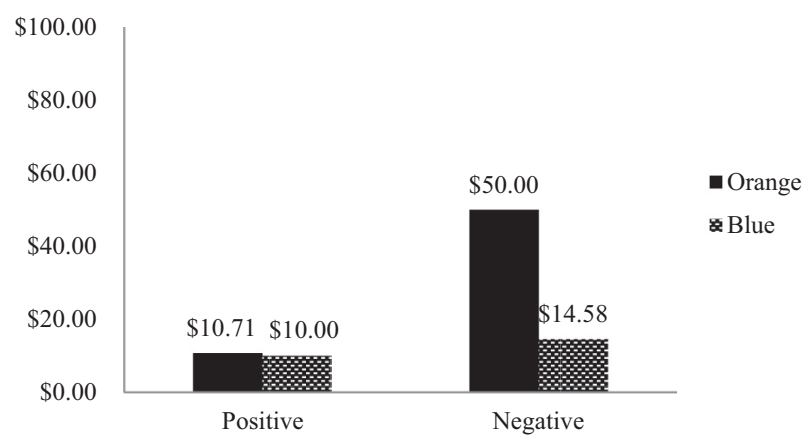

Fig. 2. Interaction of color and message on donation behavior (study 1-2 the field experiment). 
study 1-1 appeared needy because of their circumstances, regardless of whether they looked happy or sad. However, in study 1-2, we created our own appeals in conjunction with a U.S. based non-profit. It proved extremely difficult to find an appropriate image of a child who appeared both happy and needy. Considerable research suggests that perceived neediness is critical in eliciting donations (e.g., Fisher \& Ma, 2014). We suspect that the non-significant results in the positive appeal condition might be due to the lack of persuasiveness of the image itself-the victim portrayed in the image might not have been perceived to be needy enough. Indeed, a brief posttest $\left(M_{\text {age }}=35.8\right.$ years, 26 males and 34 females $)$ shows a significant difference in "perceived need for help" between the positive appeal used in this study and those used in our other studies $\left(M_{\text {field study }}=3.52 \mathrm{vs}\right.$. $M_{\text {study } 1-1}=5.04, M_{\text {study } 2}=4.71$, and $\left.M_{\text {study } 4}=5.04 ; p s<.05\right)$. In addition, this is the only charity appeal in which the victim's perceived need is below the midpoint of the scale $(t(59)=-2.45, p=.017)$. Therefore, the average donation amount was not significantly different between the people who read the two positive appeals.

\section{Study 2}

The results of studies 1-1 and 1-2 provide some support for the notion that background color moderates the effectiveness of positive and negative charity appeals. Study 2 examines the underlying mechanism for this effect. We hypothesize that incongruent color-appeal combinations increase donations by intensifying emotional responses to the ad. We expect that pairing blue with a positive appeal will accentuate positive emotions, whereas pairing orange with a negative appeal will increase negative emotions, and that this emotion-accentuation will lead to greater charitable donations. To test this hypothesis, we designed positive and negative appeals for World Help, a nonprofit organization devoted to providing humanitarian, medical, and educational assistance to children living in impoverished areas. We also included a neutral white background to see whether incongruent colorappeal combinations significantly increase donations relative to this control.

\subsection{Participants and method}

Two-hundred and thirty-nine participants $\left(M_{\mathrm{age}}=36.1\right.$ years; 121 males and 118 females $)$ were recruited online. The experiment had a 2 (appeal: positive and negative) $\times 3$ (colors: blue, orange, and white) between-subjects design, and participants were randomly assigned to one of the six conditions.

The stimuli for this study were adapted from existing charity appeals by World Help. The positive appeal consisted of a picture of a smiling child with the caption "Healthy Children, Happy World" and a statement about the importance of proper nutrition. The negative appeal contained an image of a sad, malnourished child with the caption "Hungry Children, Hopeless World," with information about the current food crisis. We decolored the picture of the child to avoid any possible confounding interaction effects between the color of the image and the background color of the ad (see Supplementary material).

We conducted a pretest to determine whether the appeals would elicit the intended emotions. The results revealed that positive appeal was rated more positive $(p<.001)$ and happy $(p<.001)$ than the negative appeal. The negative appeal was rated more negative $(p<.001)$ and sad $(p<.001)$ than the positive appeal (see Appendix $C$ for details).

In the main study, participants viewed the appeal on blue (Hue: 170, Saturation: 239, Luminance: 128), orange (Hue: 15, Saturation: 239, Luminance: 128), or white backgrounds with matching font colors (black font was used for the white background). Immediately after viewing the charity appeal, participants reported the degree to which they felt five positive (pleasant, happy, hopeful, positive, cheerful; $\alpha=0.94$ ) and five negative (sad, guilty, remorseful, pessimistic, unhappy; $\alpha=0.83$ ) emotions on a nine-point scale ( $1=$ not at all, $9=$ very much). Next, participants indicated their intention to donate to World Help on three items: "How likely are you to make a donation to this organization in the future?", "How likely are you to participate in donation to the organization in the future?" and "How likely are you to get more information about how to participate in donation?" ( 1 = not at all to $7=$ extremely; $\alpha=0.97$; modified from Bagozzi \& Moore, 1994 and Basil, Ridgway, \& Basil, 2008). Then, they were asked how much attention they paid to the stimulus on a three-item, bipolar nine-point scale (How much attention did you pay to the charity appeal? No attention (1)/Complete attention (9); How attention-grabbing do you think the charity appeal is? Not at all (1)/Extremely (9); How effective do you think the charity appeal is? Not at all (1)/Extremely (9); $\alpha=0.74$ ). Finally, participants were asked about their familiarity with the charity $(1=$ not at all familiar to $5=$ very familiar $)$ and their demographic information. Given the prohibitive costs of using actual donations and the high correlation between behavioral intention and behavior (e.g., Sheppard, Hartwick, \& Warshaw, 1988), only donation intention was measured in this study.

\subsection{Results and discussion}

\subsubsection{Intention to donate}

A 2 (appeal) $\times 3$ (color) ANCOVA with familiarity with the organization as a covariate revealed a main effect of familiarity $(F(1$, $232)=8.68, p<.01)$ and a significant interaction of color and appeal on intention to donate $(F(2,232)=6.37, p<.01)$. Pairwise comparisons showed that intention to donate was higher for the negative appeal when it appeared against the orange background than the blue background or the white background $(p s<.05)$ (see Table 1 ). However, there was no significant difference between the blue background and the white background $(p>.99)$. In contrast, intention to donate was greatest for the positive appeal

\footnotetext{
${ }^{3}$ This is measured by a four-items, seven-point scale (i.e., please rate the extent to which the need for help for the children portrayed in the appeal is (1) significant (2) severe (3) devastating (4) distressing, all alphas $(\alpha)>0.95)$
} 
Table 1

Pairwise comparisons for intention to donate (Study 2).

\begin{tabular}{lll}
\hline Means & & $p$-Value \\
\hline$M_{\text {negative-orange }}=5.59$ & $M_{\text {negative-blue }}=4.24$ & 95\% CI for difference \\
& $M_{\text {negative-white }}=4.23$ & $095-2.604$ \\
$M_{\text {positive-blue }}=6.21$ & $M_{\text {positive-orange }}=4.92$ & $0.12-2.606$ \\
& $M_{\text {positive-white }}=4.71$ & $0.019-2.55$ \\
& $0.233-2.76$ \\
\hline
\end{tabular}

when it appeared against the blue background than the orange or the white background ( $p s<.05$ ) (see Table 1 ). There was no significant difference between the orange background and the white background for the positive appeal $(p>.99)($ Fig. 3$)$.

\subsubsection{Positive emotions}

A $2 \times 3$ ANOVA revealed a main effect of appeal type, whereby the positive appeal elicited more positive emotion than the negative appeal, $F(1,232)=280.36, p<.001$. This main effect should be interpreted in light of a significant interaction between appeal type and background color, $F(2,232)=5.77, p<.01$. Participants reported feeling more positive after seeing the positive appeal against the blue background than the orange background or the white background ( $p s<.01$ ) (see Table 2). There was no significant difference in positive emotions between the orange and white backgrounds $(p>.99)$. In addition, background color did not influence ratings of positive emotions for the negative appeal $\left(M_{\text {negative-blue }}=1.67\right.$ vs. $M_{\text {negative-orange }}=1.85 ; M_{\text {negative-neutral }}=$ $2.00 ; F(2,232)<1)$.

\subsubsection{Negative emotions}

Another $2 \times 3$ ANOVA on negative emotions revealed a main effect of appeal type whereby people felt more negative after reading the negative appeal than the positive appeal $F(1,232)=87.50, p<.001$. There was also a significant interaction between color and appeal, $F(2,232)=4.28, p<.05$. Negative emotions were higher for the negative appeal when it appeared against the orange background than the blue or the white background ( $p s<.05$ ) (see Table 3 ). There was no difference between the blue and white background $(p>.99)$. Negative emotions did not vary by background color for the positive appeal $\left(M_{\text {positive-orange }}=3.56\right.$ vs. $M_{\text {positive-blue }}=3.83$ vs. $\left.M_{\text {positive-neutral }}=3.92 ; F(2,232)<1\right)$.

\subsubsection{Attention}

A $2 \times 3$ ANOVA revealed a main effect of appeal type, such that people paid more attention to the negative appeal than the positive one $F(1,232)=7.80, p<.01$. There was a marginal main effect of color, whereby colored appeals drew more attention than the black and white appeal $\left(M_{\text {blue }}=6.92, M_{\text {orange }}=7.04, M_{\text {white }}=6.48, F(2,232)=2.57, p=.079\right)$. Familiarity with the organization had a positive impact on attention as well $(F(1,232)=4.0, p<.05)$.

More pertinent to our hypothesis, there was a significant interaction between color and appeal type $(F(2,232)=6.97, p=$ $.001)$. Attention was higher for the negative appeal when it appeared against the orange background than the blue $(p<.01)$ or white background $(p<.05)$ (see Table 4$)$. There was no difference between the blue and white backgrounds $(p=1.0)$. Attention was also marginally higher for the positive appeal when it appeared against the blue background than the orange $(p=.073)$ or the white background $(p<.05)$ (see Table 4$)$.

\subsubsection{Moderation mediated by attention}

We tested whether the interaction between color as an independent variable and appeal as a moderator on intention to donate is mediated by attention, an antecedent mediator that is predicted to intensify emotion for both charity appeals. A moderated mediation bootstrapping analysis (Hayes, 2013, PROCESS model 8) was performed to examine the relationship, and the results showed that the $95 \%$ bootstrap confidence intervals did not include zero (Lower $\mathrm{CI}=-1.0189$; Upper $\mathrm{CI}=-0.3078$ ), which

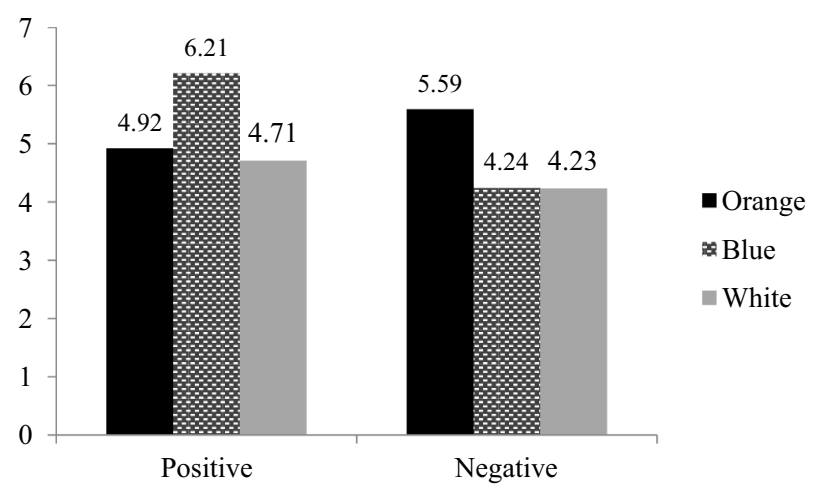

Fig. 3. Interaction of color and message on intention to donate (study 2). 
Table 2

Pairwise comparisons for positive emotions (Study 2).

\begin{tabular}{|c|c|c|c|}
\hline Means & & p-Value & $95 \% \mathrm{CI}$ for difference \\
\hline$M_{\text {positive-blue }}=6.07$ & $\begin{array}{l}M_{\text {positive-orange }}=4.82 \\
M_{\text {positive-white }}=4.84\end{array}$ & $p s<.01$ & $\begin{array}{l}0.387-2.110 \\
0.370-2.093\end{array}$ \\
\hline
\end{tabular}

confirmed that the color $\times$ emotional appeal interaction was mediated by attention. Five thousand bootstrap samples were generated for the analysis.

\subsubsection{Process testing for the negative appeal}

First, we examined the mediating role of attention and emotion on donation for orange versus blue backgrounds, using white as a covariate. For this test, two dummy variables were constructed to dummy-code three groups, such that D1 codes blue (white 0 , blue 1 , and orange 0 ) and D2 codes white (white 1 , blue 0 , and orange 0 ), with orange being the reference group. The mediation model includes intention to donate as a dependent variable, D1 as an independent variable, D2 and familiarity with the organization as covariates, attention as the first mediator, and negative emotions as the second mediator. A mediation bootstrapping analysis (Hayes, 2013, PROCESS model 6) with 5000 bootstrap samples showed that the 95\% bootstrap confidence interval did not include $0(\beta=-0.1618$, Lower $\mathrm{CI}=-0.4157$; Upper $\mathrm{CI}=-0.0141)$, suggesting that the effect of color on intention to donate was mediated by (1) attention and (2) negative emotions, sequentially as hypothesized.

Next, we replaced D2 as an independent variable and D1 as a covariate to test mediation of attention and emotions on intention to donate for the orange and white backgrounds. Results confirmed the hypothesized mediation relationship ( $\beta=-0.1349$, Lower $\mathrm{CI}=-0.3386$; Upper $\mathrm{CI}=-0.0100$ ) (see Table 5). Finally, we recoded the dummy variables and tested mediation for the blue and white conditions (D1 codes blue (white 0 , blue 1 , and orange 0 ) and D2 codes orange (white 0 , blue 0 , and orange 1 ), with white as the reference group). Results for this test were not significant ( $\beta=-0.0270$, Lower CI $=-0.1907$; Upper CI $=$ 0.1022). No mediation effects with positive emotions as the mediator were found for the negative appeal.

\subsubsection{Process testing for the positive appeal}

The same process was repeated to test the mediating role of attention and emotions for the positive appeal. We used dummy codes for the independent variable, such that D1 codes white (white 1 , blue 0 , and orange 0 ) and D2 codes orange (white 0 , blue 0 , and orange 1 ), with blue as the reference group. Five thousand bootstrap samples (Hayes, 2013, PROCESS model 6) showed that the $95 \%$ bootstrap confidence interval did not include 0 ( $\beta=-0.1113$, Lower $\mathrm{CI}=-0.2816$; Upper $\mathrm{CI}=-0.0126$ ), suggesting that the effect of color (orange vs. blue) on intention to donate was sequentially mediated by (1) attention and (2) positive emotions. Mediation for the white and blue conditions was also significant $(\beta=-0.1385$, Lower $\mathrm{CI}=-0.3309$; Upper $\mathrm{CI}=$ -0.0217 ) (see Table 6 ), but mediation for orange and white was not ( $\beta=0.0273$, Lower $\mathrm{CI}=-0.0772$; Upper CI $=0.1499$ ). Taken together, the results of study 2 provide further support for hypotheses 1 and 2 .

\section{Study 3}

This study was developed to garner support for the causal impact of attention on donation behavior by directly manipulating attention level. We suggest that attention will be heightened when color and appeal type are incongruent, which subsequently enhances donors' emotional experiences, resulting in greater donations. Based on this reasoning, a direct manipulation of attention levels should attenuate the interaction of background color and charity appeals, resulting in a main effect of attention level on donation.

\subsection{Participants and method}

Eight hundred Mturk workers participated in this study. Six participants did not complete the survey, leaving a final sample of $794\left(M_{\text {age }}=37.6\right.$ years, Males $=373$, Females 419, 2 unreported gender). We utilized a 2 (attention: low and high) $\times 2$ (color: orange and blue) $\times 2$ (appeal type: positive and negative) between-subjects design. Participants were told they would see a portion of a charity appeal from Save the Children, which was used in Study 1-1. In the high attention condition, participants were told that their opinion of the appeal would determine whether the charity would use it or not in an upcoming campaign. In the low attention condition, participants were told that they were about to see an appeal that had been used by the charity before, but probably would not be used again. A pretest $(N=70)$ indicated that our attention manipulation was successful. Participants in the

Table 3

Pairwise comparisons for negative emotions (Study 2).

\begin{tabular}{lll}
\hline Means & & $p$-Value \\
\hline$M_{\text {negative-orange }}=6.51$ & $M_{\text {negative-blue }}=5.42$ & 95\% CI for difference \\
& $M_{\text {negative-white }}=5.54$ & $0.172-2.011$ \\
& $0.061-1.883$ \\
\hline
\end{tabular}


Table 4

Pairwise comparisons for attention (Study 2).

\begin{tabular}{|c|c|c|c|}
\hline Means & & $p$-Value & $95 \% \mathrm{CI}$ for difference \\
\hline \multirow{2}{*}{$M_{\text {negative-orange }}=7.82$} & $M_{\text {negative-blue }}=6.70$ & $p s<.01$ & $0.212-2.035$ \\
\hline & $M_{\text {negative-white }}=6.90$ & $p<.05$ & $0.021-1.827$ \\
\hline \multirow[t]{2}{*}{$M_{\text {positive-blue }}=7.17$} & $M_{\text {positive-orange }}=6.31$ & $p=.073$ & $-0.055-1.783$ \\
\hline & $M_{\text {positive-white }}=6.10$ & $p<.05$ & $0.153-1.991$ \\
\hline
\end{tabular}

Table 5

Conditional indirect effects of color on donation intention (negative appeal) (Study 2).

\begin{tabular}{|c|c|c|c|c|c|c|c|c|c|}
\hline Color & Attention & LLCI & ULCI & Attention $\rightarrow$ Negative emotion & LLCI & ULCI & Negative emotion & LLCI & ULCI \\
\hline Blue vs. Orange & -0.5180 & -1.0227 & -0.1457 & -0.1618 & -0.4157 & -0.0141 & -0.1645 & -0.5115 & 0.0342 \\
\hline White vs. Orange & -0.4316 & -0.8180 & -0.1119 & -0.1349 & -0.3386 & -0.0100 & -0.1739 & -0.5666 & 0.0455 \\
\hline Blue vs. White & -0.0864 & -0.5230 & 0.2888 & -0.0270 & -0.1907 & 0.1022 & 0.0094 & -0.2174 & 0.2691 \\
\hline
\end{tabular}

Note. - LLCI/ULCI indicates lower/upper limit of the 95\% confidence interval (CI). Coefficients in bold type indicate significant conditional indirect effects (CI does not include a zero)

high attention condition reported paying more attention to the appeals than those in the low attention condition $\left(M_{\text {high }}=4.69\right.$, $\left.M_{\text {low }}=2.83, p<.001\right)$.

After viewing the charity appeals, participants were asked about their intention to donate to the charity ( 1 not at all-7 very much so). Participants were also told that they would be automatically entered into a lottery drawing for $\$ 10$ as an additional show of appreciation. We asked participants how much they would be willing to donate to the charity if they won the lottery. Participants were asked to report on the emotions they experienced when viewing the appeal on the same five positive $(\alpha=$ $0.96)$ and five negative $(\alpha=0.89)$ emotions used in Study 2 . Familiarity with the organization was measured on the same scale as before. After reporting their demographic information, participants were dismissed from the study.

\subsection{Results}

\subsubsection{Donation intention}

We conducted a three-way ANCOVA with color (orange and blue), appeal type (positive and negative), and attention level (high and low) as predictors and familiarity with the charity as a covariate. As expected, the main effect of attention was significant $(F(1,785)=10.21, p=.001)$, such that donation intention in the high attention condition was greater than that in the low attention condition. There was also a marginal effect of appeal type such that donation intention was greater for the negative appeal than the positive appeal $(F(1,785)=3.40, p=.065)$. Familiarity with the organization had a positive effect on donation intention $(F(1,785)=37.24, p<.001)$. No other effects were significant $(p s>.15)$.

\subsubsection{Donation amount}

A three-way ANCOVA with donation amount as the DV revealed a main effect of attention, such that donations were greater in the high (vs. low) attention condition $(F(1,785)=5.10, p=.024)$. No other main or interaction effects were found $(p s>.10)$.

\subsubsection{Positive emotions}

Another $2 \times 2 \times 2$ ANCOVA revealed a main effect of appeal type on positive emotions, where the positive appeal elicited more positive emotions than the negative one $(F(1,785)=167.25, p<.001)$. A significant interaction between attention level and appeal type was also found $(F(1,785)=5.69, p=.017) .{ }^{4}$ Familiarity with the organization enhanced positive emotions $(p<.001)$ No other main or interaction effect was found ( $p s>.11$ ).

\subsubsection{Negative emotions}

The $2 \times 2 \times 2$ ANCOVA revealed a main effect of appeal type, such that people experienced more negative emotions after reading the negative appeal than the positive one $(F(1,785)=113.71, p<.001)$. A two-way interaction effect of attention and charity appeal was marginally significant $(F(1,785)=2.90, p=.09) .{ }^{5}$ The three-way interaction effect was also marginally significant $(F$

\footnotetext{
${ }^{4}$ We conducted another ANCOVA with appeal type and attention level as predictors and familiarity as a covariate to look into this significant 2 -way interaction. The results revealed that participants felt more positive emotions from the positive appeal in the high (vs. low $)$ attention level $\left(M_{\text {high }}=5.35, M_{\text {low }}=4.91, F(1,789)=3.78\right.$, $p=.052)$, but not from the negative appeal $\left(M_{\text {high }}=2.91, M_{\text {low }}=3.21, F(1,789)=1.86, p>.17\right)$.

${ }^{5}$ We conducted another ANCOVA with appeal type and attention level as predictors and familiarity as a covariate to look into this marginally significant 2-way interaction. The results revealed that participants felt more negative emotions from the negative appeal in the high (vs. low) attention level, but this difference was not significant $\left(M_{\text {high }}=5.12, M_{\text {low }}=4.81, F(1,789)=2.27, p>.13\right)$. There was no difference in the positive appeal condition $\left(M_{\text {high }}=3.28, M_{\text {low }}=3.47, F(1\right.$, 789) $=0.89, p>.34)$.
} 
Table 6

Conditional indirect effects of color on donation intention (positive appeal) (Study 2).

\begin{tabular}{|c|c|c|c|c|c|c|c|c|c|}
\hline Color & Attention & LLCI & ULCI & Attention $\rightarrow$ Positive emotion & LLCI & ULCI & Positive emotion & LLCI & ULCI \\
\hline Orange vs. Blue & -0.4664 & -0.9302 & -0.0940 & -0.1113 & -0.2816 & -0.0126 & -0.3760 & -0.8145 & -0.0362 \\
\hline White vs. Blue & -0.5808 & -1.1732 & -0.1565 & -0.1385 & -0.3309 & -0.0217 & -0.3427 & -0.7989 & -0.0221 \\
\hline Orange vs. White & 0.0144 & -0.2552 & 0.5828 & 0.0273 & -0.0772 & 0.1499 & -0.0333 & -0.3337 & 0.3049 \\
\hline
\end{tabular}

Note. - LLCI/ULCI indicates lower/upper limit of the 95\% confidence interval (CI). Coefficients in bold type indicate significant conditional indirect effects (CI does not include a zero).

$(1,785)=2.90, p=.089)$, but the two decomposed two-way interactions between colors and charity appeals in terms of attention level were not significant $(p s>.18)$. No other main or interaction effect was found $(p s>.67)$.

\subsubsection{Process testing for the positive appeal}

A mediation analysis with 10,000 bootstrap samples and positive emotions as the mediator (Hayes, 2013, PROCESS model 4) revealed a significant indirect effect of positive emotions on both donation amount $(\beta=0.2127,95 \%$ Lower CI $=0.0061$; Upper $\mathrm{CI}=0.4796)$ and donation intention $(\beta=0.1788,95 \%$ Lower $\mathrm{CI}=0.0013$; Upper $\mathrm{CI}=0.3687$ ). High attention intensified positive emotional responses, which increased both donation amount and donation intention for the positive appeal. Indirect effects with negative emotions as a mediator for the positive appeal were not found.

\subsubsection{Process testing for the negative appeal}

An analysis for the negative appeal revealed non-significant mediation effects for donation amount $(\beta=0.0712,95 \%$ Lower $\mathrm{CI}=-0.0122$; Upper $\mathrm{CI}=0.2182)$ and donation intention $(\beta=0.0460,95 \%$ Lower $\mathrm{CI}=-0.0112$; Upper $\mathrm{CI}=0.1360)$. There were no indirect effects with negative emotions as the mediator for the positive appeal.

\subsection{Discussion}

The results of this study support our moderated mediation hypothesis for the positive appeal. Surprisingly, we obtained nonsignificant mediation effects for the negative appeal. We suspect that this is due to the way attention was manipulated in the study. Prior research distinguishes between stimulus-driven attention and goal-driven attention (Orquin \& Loose, 2013). Stimulus-driven attention relates to the characteristics of the stimulus such as location and salience, whereas goal-driven attention is dependent on the respondents' decision goals (Meißner, Musalem, \& Huber, 2016). Importantly, stimulus-driven attention seems to occur more automatically than goal-driven attention. Previously, we measured attention from the incongruence of color and appeal type, which is likely stimulus-driven. However, the manipulated attention in the current study was more likely to be goal-driven, as participants had predetermined goals relating to whether they should pay attention to the appeals. Further, people are more willing to experience higher levels of positive emotions than negative ones. Thus, in the case of goal-driven attention, the effect of emotional stimuli on positive emotions, and the effect of positive emotions on subsequent behaviors should be stronger than for negative emotions.

The fact that the interaction effect of color and appeal type was attenuated in the high attention condition was expected-people in the high attention condition will pay attention to the stimuli regardless of the incongruence effect. However, we also found an attenuation of the interaction effect of color and appeal type in the low attention condition. We surmise that this is due to participants' information processing goals in the low attention condition-the manipulation instructions informed participants that the appeal they were about to see would not be used by the charity in the future. Therefore, it is likely that people were not motivated to pay attention to their assigned charity appeal. However, people might be less reluctant to pay attention to the positive appeal compared to the negative appeal even in the low attention condition, so the stimulus-driven incongruence effect may continue to influence behavior for positive appeals. Further exploration of the data showed a focused contrast effect of color on donation intention for the positive appeal in the low attention condition $\left(M_{\text {positive+blue }}=4.39, M_{\text {positive }+ \text { orange }}=3.88, F(1,785)=4.38\right.$, $p<.05)$, whereas such an effect did not exist for the negative appeal $\left(M_{\text {negative+blue }}=4.34, M_{\text {negative+orange }}=4.40, F(1\right.$, $785)<1$ ). In a follow-up study (see Appendix D), we used different attention levels - i.e., high attention vs. control - and were able to replicate the pattern of results pertaining to the interaction of color and appeal type that we obtained in our prior studies in the control condition $\left(M_{\text {positive-blue }}=\$ 5.83\right.$ vs. $M_{\text {positive-orange }}=\$ 4.88, F(1,820)=4.22, p<.05 ; M_{\text {negative-orange }}=$ $\$ 5.92$ vs. $\left.M_{\text {negative-blue }}=\$ 4.99, F(1,820)=3.87, p<.05\right)$. As expected, the congruency effect was attenuated in the high attention condition.

In sum, this study shows the effect of attention on donation by directly manipulating attention, and examines the mediating role of emotional responses. This study provides further support for the mechanism uncovered in Study 2 . In the next study, we examine a potential boundary condition for the effect.

\section{Study 4}

Prior research shows that when consumers are made aware that their emotion is influenced by an external source, they are no longer influenced by that emotion (Di Muro \& Murray, 2012; Kim et al., 2010; Schwarz \& Clore, 1983). We test this hypothesis in a 
donation context in Study 4. We designed a set of stimuli for this study based on ads for Save the Children (see Supplementary material). We conducted a pretest to ensure that the positive and negative charity appeals elicited the intended reactions, and found that the positive appeal was rated more positive $(p<.05)$ and happy $(p<.001)$ than the negative appeal. The negative appeal was rated more negative $(p<.05)$ and sad $(p<.001)$ than the positive appeal (see Appendix E for details).

In the main study, we randomly assigned participants to one of eight conditions in a 2 (awareness: color vs. music $($ control) $) \times 2$ (color: orange vs. blue) $\times 2$ (charity appeal: positive vs. negative) between-subjects design. We recruited 231 participants ( $M_{\text {age }}=34.1$ years; 137 males and 94 females) from MTurk. Participants first completed the awareness induction task, in which they were made aware of the effect of color on emotions (manipulation condition) or music on emotions (control condition). This was done by asking participants to read a recent news article on the relevant topic (see Supplementary material). After reading the assigned article, participants were asked the extent to which they agreed with the article (i.e., to what extent do you agree that music (color) affects mood? 1: strongly disagree to 7: strongly agree). This served as a manipulation check. In both the music and color awareness conditions, the level of agreement was higher than the median value $\left(M_{\text {music }}=6.32\right.$ vs. $4.00, t(110)=6.32, p<.001 ; M_{\text {color }}=5.73$ vs. 4.00 , $t(119)=5.73, p<.001)$, suggesting the manipulation successfully raised perceptions that external cues can affect emotions.

After finishing the first phase of the task, participants were told that they would be completing a separate, unrelated study. They were then randomly assigned to view a charity appeal (positive, negative) against a colored background (orange, blue). We used the same color model as our other studies (Blue - Hue: 170, Saturation: 239, Luminance: 128; Orange - Hue: 15, Saturation: 239, Luminance: 128). After answering filler questions about the appeal, participants were thanked for their participation and told that they would be automatically entered into a lottery for $\$ 10$ as an extra show of appreciation. We asked how much they would donate to Save the Children if they won the lottery. Participants could respond with any number, from $\$ 0$ to $\$ 10$. This served as our main variable of interest. After reporting familiarity with the organization and demographic information, they were dismissed.

\subsection{Results}

A $2 \times 2 \times 2$ ANCOVA with awareness condition, color, and appeal type as predictors and familiarity with the organization as a covariate revealed a significant two-way interaction between color and appeal $(F(1,222)=4.45, p<.05)$ and a three-way interaction $(F(1,222)=5.03, p<.05)$. In the control (music awareness) condition, replicating previous results, the interaction of color and appeal type was significant $(F(1,222)=9.18, p<.01)$. Pairwise comparisons showed that the positive-blue appeal was more effective than the positive-orange one ( $M_{\text {positive-blue }}=\$ 5.17 \mathrm{vs}$. $M_{\text {positive-orange }}=$ $\$ 3.39, F(1,222)=4.83, p<.05)$, and the negative-orange appeal was more effective than the negative-blue one $\left(M_{\text {negative-orange }}=\$ 5.24\right.$ vs. $\left.M_{\text {negative-blue }}=\$ 3.25, F(1,222)=4.44, p<.05\right)$. However, the interaction effect disappeared in the color awareness condition $(F(1,222)<1)$. That is, when participants were made aware that their emotions could be influenced by color, neither positive nor negative charity appeal effectiveness differed by background color $\left(M_{\text {positive-blue }}=\$ 3.75\right.$ vs. $M_{\text {positive-orange }}=\$ 4.76, F(1,222)=1.22, p>.27 ; M_{\text {negative-orange }}=\$ 4.01$ vs. $\left.M_{\text {negative-blue }}=\$ 3.12, F(1,222)=1.28, p>.26\right)$ (see Figs. 4 and 5). The results comport with previous research showing that emotion-induced biases are erased once people are aware that their emotions may be influenced by relevant external cues. This study provides further support for our proposed mechanism of and aligns with Hypothesis 3.

\section{Study 4 results (Music-mood awareness control condition)}

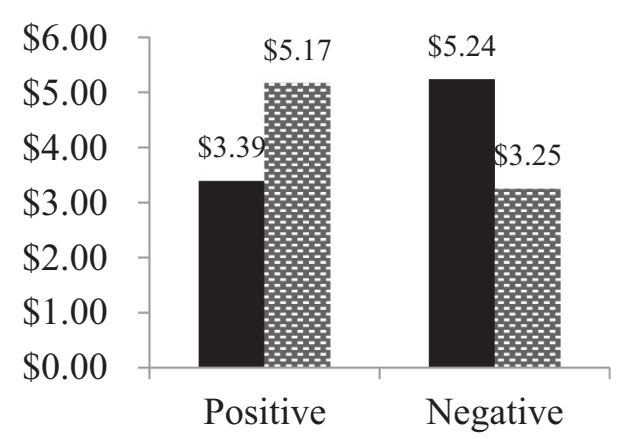

\section{Study 4 results (Color-mood awareness experimental condition)}

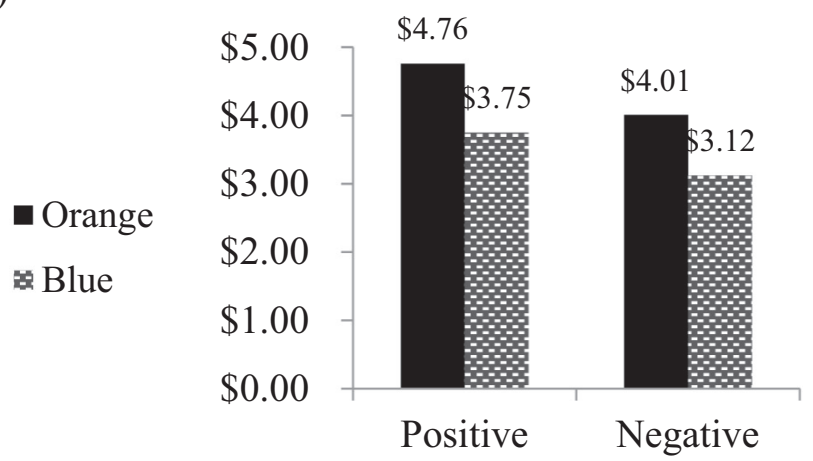

- Orange

s Blue

Figs. 4 and 5. Interaction of awareness of color impact, color, and message on donation behavior (study 4). 


\section{General discussion}

There are over 1.5 million nonprofit organizations in the United States (National Center for Charitable Statistics, 2017) that compete with one another to raise funds for their causes. As the demand for the help that these organizations provide increases, nonprofit marketers need to find novel ways to sustain their fundraising efforts and enhance the effectiveness of their donation appeals. The current research builds upon extant work on donation behavior, color psychology and incongruence effects to show that the strategic use of certain background colors with both positively- and negatively-valenced charity appeals will attract the attention of potential donors and bolster their donation behavior by intensifying their emotional response to the appeals. In doing so, we highlight the critical role played by incongruent contextual cues in influencing prosocial behavior.

Prior research finds that both positive- and negative-valenced charity appeals can stimulate donation behavior. However, there is little research on the impact of background color on the effectiveness of charity appeals, which is rather surprising given the importance of visual cues in today's image-laden media environment. In view of the fact that people pay more attention to information that is incongruent (vs. congruent) with an elicited schema (Moore et al., 2005), we hypothesized and showed that charity appeals presented against an incongruent background color elicit more attention. Increased attention to the charity appeal magnifies the emotional intensity experienced by potential donors, which ultimately influences their donations.

In addition to delineating the process by which congruency impacts donation behavior, we also explored a boundary condition for the focal effect. We posited that if potential donors are informed about the source of their felt emotions (e.g., Di Muro \& Murray, 2012) in response to the visual stimuli, then the effect of emotions on donation behavior will be attenuated. We find this to be true-the effect of incongruent background color on the effectiveness of charity appeals is diminished if people are made aware of the association between color and emotions.

The current research makes several contributions to extant literature. Prior research in advertising (Meyers-Levy \& Peracchio, 1995) suggests that the use of colors can, at times, be detrimental to the evaluation of the advertised product, depending on the availability of cognitive resources. Lee et al. (2014) suggest that using colors in ads can potentially distract consumers from paying attention to the primary product claims in the ad by evoking low-level construal. This research finds that the use of select background colors with emotional charity appeals can enhance the attention people pay to the message and increase the effectiveness of the appeal in stimulating donation behavior. Our results are consistent with other studies showing that both positive and negative emotions can increase prosocial behavior (Cialdini et al., 1982; Cunningham et al., 1980; Weyant, 1978), and contribute to the broader charitable giving literature.

The results of this research provide nonprofit organizations with guidance on when and why emotional charity appeals evoke different levels of attention, emotional responses and donation behavior. Charities might use different types of emotional appeals depending on the cause that they support. For example, a positive appeal would be a better fit for a community soccer team's fundraising effort. On the other hand, a negative appeal might be more appropriate when requesting provisions for children living in a war zone. Our research suggests that the former type of appeal might be more effective against a blue background, while the latter type will garner more support if presented against an orange background.

\subsection{Limitations and future directions}

The current research is not without limitations. In the field study (1-2), we found that people donated significantly more money when they read a negative appeal against an orange (vs. blue) background. However, donations for the positive appeal against the blue and orange backgrounds did not differ. We suspect that the non-significant results were due to the nature of the image in the charity letter. The results of our posttest suggest the victim in the positive appeal was not perceived as being particularly needy, and perceived neediness might be an important predictor of donation behavior. In addition, given the nature of email campaigns, we had no means to detect whether people had actually opened the email to read the message or had simply clicked "mark as read." Thus, it was difficult to determine the correct sample size to measure behavior. We set the sample size to those who had actually interacted with the appeals by clicking on the donation button. However, we acknowledge that tracking the outcome of each email more rigorously (e.g., with email tracking software) would be ideal.

Another limitation of this research is that we focused solely on the valence of the elicited emotions (e.g., pleasantness-sadness) and did not test whether other factors such as cognitive appraisal and information processing were affected. To help address this issue, we conducted posttests for all stimuli in the paper and report the details in Supplementary material. We measured eight cognitive appraisal dimensions (e.g., pleasantness, legitimacy, control, certainty), using the same items as Smith and Ellsworth (1985). While all the emotional appeals affected pleasantness, their effects on other appraisals were largely not significant. We also measured information processing using Kimchi and Palmer's (1982) figure stimuli, and the results showed no significant difference in global versus local processing in any of our studies. Although previous studies support the relationship between mood and information processing (Gasper \& Clore, 2002), the evoked emotions from viewing our emotional charity appeals might not be strong enough to activate different types of information processing.

We acknowledge that there is a potential confound from the different number of beneficiaries in the positive and negative appeals in several of our studies (i.e., Study 1-1, Study 3, and Study 4). Nevertheless, we found consistent effects when using appeals with the same number of victims in the field study and in Study 2, which boosts our confidence that the effects were not driven by the number of beneficiaries in the manipulations.

Another limitation of this research is that it was conducted in one culture. Elliot et al. (2007) suggest that colors can have different consequences for cognition and behavior based on the context. People from different cultures automatically associate colors 
with different concepts through a lifetime of learning and reinforcement. For instance, people in the United States have an automatic preference for the color white over black (Kareklas, Brunel, \& Coulter, 2013), which has important implications for product sales (e.g., car paint colors) and ad execution (e.g., racial ethnicity in advertising messages). However, the color white signifies death in Japan and sterility in Eastern cultures (Akcay, Dalgin, \& Bhatnagar, 2011). Future research should identify background colors that are incongruent with positive and negative emotional charity appeals in other cultures, so that non-profit marketers from across the globe can benefit from this information.

To examine the effect of background colors in a clear and systematic manner, we selectively used orange and blue in our ads. We tried to replicate the effects with yellow and purple, the colors closest to orange and blue on the color wheel, but were largely unsuccessful. We speculate that the level of incongruence from these two background colors with the charity appeals might not be strong enough to draw participants' attention to the stimuli. In fact, we tested the level of incongruence between positive and negative appeals and the color yellow (Hue: 40, Saturation: 239, Luminance: 128) and purple (Hue: 188, Saturation: 239, Luminance: $128)$. We were not able to find an interaction between color and charity appeal on perceived incongruence $(F(1,117)=0.37$, $p>$.54). The wavelength of yellow is shorter than orange, which may be why it is not perceived to be as warm as orange. Purple might not be as strongly associated with sadness as blue. It would be prudent for future research to examine whether our effects generalize to other colors that are associated with positive and negative emotions.

Further, it should be noted that our experiments controlled for both saturation and luminance and varied only the hue. However, saturation and luminance can also influence emotions (Gorn, Chattopadhyay, Yi, \& Dahl, 1997; Hagtvedt \& Brasel, 2017; Valdez \& Mehrabian, 1994). Future studies should investigate the role of saturation and luminance on the effectiveness of charity appeals. Relatedly, it would be fruitful for future research to explore other emotional effects of color besides valence. For example, studies suggest that, in some situations, blue produces feelings of relaxation while red increases feelings of excitement or aggression (e.g., Labrecque \& Milne, 2012). Such research speaks to the arousal dimension of emotion (e.g., Watson \& Tellegen, 1985), and can influence the evaluations of ads (Gorn, Pham, \& Sin, 2001).

Importantly, the effect of color may vary depending on the context. The color-in-context model suggests that the influence of color on behavior varies as a function of the psychological context in which it is perceived. For instance, red increases approach tendencies in a romantic context and avoidance tendencies in an achievement related context (Meier, D'Agostino, Elliot, Maier, \& Wilkowski, 2012). Knowing the circumstances in which the same color can produce different effects will undoubtedly be valuable to some organizations.

Drawing on the current work, one area that is ripe for research in the charitable giving context is the exploration of how different aspects of a charity appeal interact with one another to influence prosocial behavior. For instance, Grinstein et al. (2019) demonstrate that simultaneously including two visual cues (i.e., one modality) - an aesthetically pleasing image of an individual and a displeasing image of a group - enhances the empathy felt by the reader and promotes prosocial behavior. How then, would the inclusion of cues belonging to different modalities (audio, visual, olfactory, etc.) in an emotional charity appeal influence prosocial behavior? Televised charity appeals often have sad music accompanying requests for support. Would an incongruous background music-emotional appeal combination produce the same contextual effects observed in our research?

\section{Conclusion}

Emotional appeals are often the most effective way to reach potential donors, and both positive and negative affect can increase helping behavior. Drawing on color psychology and schema incongruity, the current research proposes a way to intensify the feelings induced by emotional charity ads, thus increasing their effectiveness. Combining a color that elicits negative valence with a positive charity appeal, or a color that elicits positive valence with a negative charity appeal, results in an increase in attention and subsequent enhancement of positive and negative affect, respectively. These incongruent color-appeal combinations lead to greater donations and donation intentions, but the effects are erased when consumers are aware of the cause of their emotions. Taken together, these findings suggest that changes to a charity advertisement's background color can lead to shifts in donors' attention, feelings and generosity.

\section{Appendix A. Pretest for Study 1-1}

A pretest was conducted to ensure that the positive and negative ads were perceived to be positive and negative, respectively. One hundred and thirty-three students $\left(M_{\mathrm{age}}=20.75\right.$ years (one participant did not answer), 72 males and 61 females) from a large Midwest university were recruited and randomly assigned to view one of the two advertisements on a white background. After viewing them at their own pace, participants answered several questions about the ad. Participants were asked to respond on a 7-point scale $(1=$ completely disagree to $7=$ completely agree) the extent to which they agreed with the following statements: "This was a positive ad," "This was a negative ad," "This was a happy ad," "This was a sad ad." Next, participants were asked how memorable and interesting the ad was ( $1=$ not at all, $5=$ extremely) in order to address these potential confounds. The results of this study showed that the positive ad was indeed rated more positive $\left(M_{\text {positive ad }}=4.94\right.$ vs. $M_{\text {negative ad }}=2.88 ; F$ $(1,132)=74.80, p<.001)$ and happy $\left(M_{\text {positive ad }}=3.92\right.$ vs. $\left.M_{\text {negative ad }}=2.15 ; F(1,131)=74.93, p<.001\right)$ than the negative ad. The negative ad was rated more negative $\left(M_{\text {negative ad }}=4.58\right.$ vs. $\left.M_{\text {positive ad }}=2.91 ; F(1,131)=53.06, p<.001\right)$ and sad $\left(M_{\text {negative ad }}=5.69\right.$ vs. $\left.M_{\text {positive ad }}=4.15 ; F(1,131)=55.51, p<.001\right)$ than the positive ad. There were no significant differences on ratings of how memorable and interesting the ads were $(p s>.10)$. 


\section{Appendix B. Pretest for Study 1-2}

We conducted a pretest to make sure the positive (negative) appeal is perceived as more positive (negative) than the negative (positive) appeal. Eighty-two Mturk participants $\left(M_{\text {age }}=35.3\right.$ years, 41 males and 41 females) were recruited and randomly assigned to view either the positive ad or the negative ad on a white background. Using the same pretest measures as in study 1-1, participants were asked to rate the extent to which they agreed with the following statements: "This was a positive ad," "This was a negative ad," "This was a happy ad," "This was a sad ad." Afterwards, participants were asked to rate how memorable and interesting the charity appeal was. As expected, the positive ad was rated more positive $\left(M_{\text {positive ad }}=5.90\right.$ vs. $M_{\text {negative ad }}=$ $3.44 ; F(1,80)=57.29, p<.001)$ and happy $\left(M_{\text {positive ad }}=5.39\right.$ vs. $\left.M_{\text {negative ad }}=2.32 ; F(1,80)=150.91, p<.001\right)$ than the negative ad. Similarly, the negative ad was perceived as more negative $\left(M_{\text {negative ad }}=4.51\right.$ vs. $M_{\text {positive ad }}=1.85 ; F(1,80)=144.89$, $p<.001)$ and sad $\left(M_{\text {negative ad }}=5.78\right.$ vs. $\left.M_{\text {positive ad }}=2.74 ; F(1,80)=81.49, p<.001\right)$ than the positive ad. No difference was observed on ratings of how memorable and interesting the ads were $(p s>.25)$.

\section{Appendix C. Pretest for Study 2}

We recruited forty-two participants ( $M_{\mathrm{age}}=33.2$ years, 27 males and 15 females) online and randomly assigned them to view one of the two appeals on a white background. We used the same scales from the Study 1-1 pretest to measure perceptions of how positive, negative, happy, and sad the appeal was. We also measured how memorable and interesting the appeal was to make sure these potential confounds were controlled for. The results of an ANOVA with charity appeal (positive, negative) as a predictor showed that the positive appeal was rated more positive $\left(M_{\text {positive ad }}=6.24\right.$ vs. $M_{\text {negative ad }}=2.67 ; F(1,40)=76.01$, $p<.001)$ and happy ( $M_{\text {positive ad }}=5.43$ vs. $\left.M_{\text {negative ad }}=1.24 ; F(1,40)=238.28, p<.001\right)$ than the negative appeal. The negative appeal was rated more negative $\left(M_{\text {negative ad }}=5.29\right.$ vs. $\left.M_{\text {positive ad }}=1.76 ; F(1,40)=89.77, p<.001\right)$ and sad $\left(M_{\text {negative ad }}=6.71\right.$ vs. $\left.M_{\text {positive ad }}=2.86 ; F(1,40)=139.30, p<.001\right)$ than the positive appeal. No differences were found on ratings of how memorable and interesting the ads were $(p s>.10)$.

\section{Appendix D. Follow-up study for Study 3}

The purpose of the study was to test a boundary condition for the focal interaction effect of color and appeal type on donation behavior. We manipulated donors' attention level, and hypothesized that the interaction effect will exist only when goals are not pre-determined.

\section{D.1. Participants and method}

We were presented with an opportunity to collect data from close to 300 students at a large university in the Midwest. However, due to the study design and recent calls for increasing power in experimental research (Meyvis \& Van Osselaer, 2018), we decided to supplement these data with additional online participants (Jones \& Neria, 2015; Paolacci, Chandler, \& Ipeirotis, 2010). Five hundred and thirty-one Mturk workers and two hundred and ninety-eight students from a large Midwest university participated in the study $\left(M_{\text {age }}=30.8\right.$ years, Males $=450$, Females 379 ). We utilized a 2 (attention: control and high) $\times 2$ (color: orange and blue) $\times 2$ (appeal type: positive and negative) between-subjects design. Participants were randomly assigned to see one of the charity appeals from Save the Children. The texts of the appeals were the same as the texts used in Study 1-1 and Study 3, but had slightly different victim images (see Supplementary material).

We used the same manipulation for the high attention condition as in Study 3, such that participants were told that their opinion about the appeal would determine whether the charity would use it or not in an upcoming campaign. In the control condition, consistent with the studies in this paper that did not manipulate attention, participants were simply told that they were about to see a charity appeal. We used the same procedure from previous studies to measure donation behavior by asking participants how much they would be willing to donate if they won the $\$ 10$ lottery. Familiarity with the organization was measured on the same scale as before. Participants were dismissed after reporting their demographic information.

\section{D.2. Results}

A three-way ANCOVA with color (orange and blue), appeal type (positive and negative), and attention level (high and control) as predictors and familiarity with the charity as a covariate revealed a significant two-way interaction between color and appeal $(F(1,820)=4.21, p<.05)$ and a significant three-way interaction effect $(F(1,820)=3.88, p<.05)$. Familiarity with the organization also had a marginal positive impact on donation $(F(1,820)=3.50, p=.062)$. No other effects were significant ( $p s>.12$ ). In the control condition, the 2 -way interaction of color and appeal type was significant $(F(1,820)=8.08, p<.01)$. Pairwise comparisons showed that the positive-blue appeal was more effective than the positive-orange one $\left(M_{\text {positive-blue }}=\right.$ $\$ 5.83$ vs. $\left.M_{\text {positive-orange }}=\$ 4.88, F(1,820)=4.22, p<.05\right)$, and the negative-orange appeal was more effective than the negative-blue one $\left(M_{\text {negative-orange }}=\$ 5.92\right.$ vs. $\left.M_{\text {negative-blue }}=\$ 4.99, F(1,820)=3.87, p<.05\right)$. However, the interaction effect disappeared in the high attention condition $(F(1,820)<1)$. When participants paid greater attention to the charity appeal, neither positive nor negative charity appeal effectiveness differed by background color $\left(M_{\text {positive-blue }}=\$ 5.40\right.$ vs. $M_{\text {positive-orange }}=$ $\$ 5.20, F(1,840)<1 ; M_{\text {negative-orange }}=\$ 5.83$ vs. $\left.M_{\text {negative-blue }}=\$ 6.00, F(1,820)<1\right)$. The results confirmed that donation 
behavior was less influenced by the incongruence of color and appeal type when they were already motivated to pay attention to the charity appeal, whereas the incongruence effect existed when goals were not pre-determined.

\section{Appendix E. Pretest for Study 4}

Forty-eight participants ( 26 males and 22 females, $M_{\text {age }}=39.0$ years) were recruited online and randomly assigned to look at one of the newly designed charity appeals on a white background. As in the previous pretests, participants were asked how positive, negative, happy, sad, memorable, and interesting the ad is. The results of ANOVA showed that the positive appeal was rated more positive $\left(M_{\text {positive ad }}=5.54\right.$ vs. $\left.M_{\text {negative ad }}=4.58 ; F(1,46)=5.91, p<.05\right)$ and happy $\left(M_{\text {positive ad }}=4.71\right.$ vs. $M_{\text {negative ad }}=$ 2.79; $F(1,46)=21.36, p<.001)$ than the negative appeal. The negative appeal was rated more negative $\left(M_{\text {negative ad }}=3.71 \mathrm{vs.}\right.$ $\left.M_{\text {positive ad }}=2.63 ; F(1,46)=5.67, p<.05\right)$ and sad $\left(M_{\text {negative ad }}=5.17\right.$ vs. $\left.M_{\text {positive ad }}=3.67 ; F(1,46)=17.58, p<.001\right)$ than the positive appeal. The results showed no differences on ratings of how memorable and interesting the ad was $(p s>.10)$.

\section{Appendix F. Supplementary data}

Supplementary data to this article can be found online at https://doi.org/10.1016/j.jiresmar.2020.02.001.

\section{References}

Akcay, O., Dalgin, M. H., \& Bhatnagar, S. (2011). Perception of color in product choice among college students: A cross-national analysis of USA, India, China and Turkey. International Journal of Business and Social Science, 2(21), 42-48.

Bagchi, R., \& Cheema, A. (2013). The effect of red background color on willingness-to-pay: The moderating role of selling mechanism. Journal of Consumer Research, 39 (5), 947-960.

Bagozzi, R. P., \& Moore, D. J. (1994). Public service advertisements: Emotions and empathy guide prosocial behavior. Journal of Marketing, 58(1), 56-70.

Basil, D. Z., Ridgway, N. M., \& Basil, M. D. (2008). Guilt and giving: A process model of empathy and efficacy. Psychology \& Marketing, 25(1), 1-23.

Batson, C. D., Batson, J. G., Griffitt, C. A., Barrientos, S. J., Brandt, R., Sprengelmeyer, P., \& Bayly, M. J. (1989). Negative-state relief and the empathy-altruism hypothesis. Journal of Personality and Social Psychology, 56(6), 922-933.

Batson, C. D., Duncan, B. D., Ackerman, P., Buckley, T., \& Birch, K. (1981). Is empathic emotion a source of altruistic motivation? Journal of Personality and Social Psychology, 40(2), 290-302.

Boudewyns, P. A. (1976). A comparison of the effects of stress vs. relaxation instruction on the finger temperature response. Behavior Therapy, 7(1), 54-67.

Burke, M. C., \& Edell, J. A. (1989). The impact of feelings on ad-based affect and cognition. Journal of Marketing Research, 26(1), 69-83.

Cialdini, R. B., Baumann, D. J., \& Kenrick, D. T. (1981). Insights from sadness: A three-step model of the development of altruism as hedonism. Developmental Review, 1 , 207-223.

Cialdini, R. B., Darby, B. L., \& Vincent, J. E. (1973). Transgression and altruism: A case for hedonism. Journal of Experimental Social Psychology, 9(6), 502-516.

Cialdini, R. B., Kenrick, D. T., \& Baumann, D. J. (1982). Effects of mood on prosocial behavior in children and adults. In N. Eisenberg (Ed.), The development of prosocial behavior (pp. 339-359). NY: Academic Press.

Cialdini, R. B., Schaller, M., Houlihan, D., Arps, K., Fultz, J., \& Beaman, A. L. (1987). Empathy-based helping: Is it selflessly or selfishly motivated? Journal of Personality and Social Psychology, 52(4), 749-758.

Clark, M. S., \& Isen, A. M. (1982). Toward understanding the relationship between feeling states and social behavior. In A. H. Hastorf, \& A. M. Isen (Eds.), Cognitive social psychology (pp. 73-108). NY: Elsevier Science.

Crawford, D. G., Friesen, D. D., \& Tomlinson-Keasey, C. (1977). Effects of cognitively induced anxiety on hand temperature. Biofeedback and Self-Regulation, 2(2), 139-146.

Crocker, J., Hannah, D., \& Weber, R. (1983). Person memory and causal-attributions. Journal of Personality and Social Psychology, 44, 55-66.

Cunningham, M. R., Steinberg, J., \& Grev, R. (1980). Wanting to and having to help: Separate motivations for positive mood and guilt-induced helping. Journal of Personality and Social Psychology, 38(2), 181-192.

Di Muro, F., \& Murray, K. B. (2012). An arousal regulation explanation of mood effects on consumer choice. Journal of Consumer Research, 39(3), 574-584.

Edell, J. A., \& Burke, M. C. (1987). The power of feelings in understanding advertising effects. Journal of Consumer Research, 14(3), 421-433.

Eimer, M., Holmes, A., \& McGlone, F. P. (2003). The role of spatial attention in the processing of facial expression: An ERP study of rapid brain responses to six basic emotion. Cognitive, Affective, E' Behavioral Neuroscience, 3(2), 97-110.

Elliot, A. J., Maier, M. A., Moller, A. C., Friedman, R., \& Meinhardt, J. (2007). Color and psychological functioning: The effect of red on performance attainment. Journal of Experimental Psychology, 136(1), 154-168.

Elliot, A. J., \& Niesta, D. (2008). Romantic red: Red enhances men's attraction to women. Journal of Personality and Social Psychology, 95(5), 1150-1164.

Fehrman, K. R., \& Fehrman, C. (2004). Color: The secret influence (2nd ed.). New Jersey: Prentice Hall Inc.

Fenko, A., Hendrik, N. J., \& Schifferstein, P. H. (2010). Looking hot or feeling hot: What determines the product experience of warmth? Materials and Design, 31(3), $1325-1331$.

Fisher, R. J., \& Ma, Y. (2014). The price of being beautiful: Negative effects of attractiveness on empathy for children in need. Journal of Consumer Research, 41(2), 436-450.

Fiske, S. T., Kinder, D. R., \& Larter, W. M. (1983). The novice and the expert: Knowledge-based strategies in political cognition. Journal of Experimental Social Psychology, 19(4), 381-400.

Gasper, K., \& Clore, G. L. (2002). Attending to the big picture: Mood and global versus local processing of visual information. Psychological Science, 13(1), 34-40.

Giving USA Foundation (2017). Giving USA 2017: The annual report on philanthropy for the year 2016. Retrieved from https://givingusa.org/.

Goodstein, R. C. (1993). Category-based applications and extensions in advertising: Motivating more extensive ad processing. Journal of Consumer Research, 20(1), 87-99.

Gorn, G., Pham, M. T., \& Sin, L. Y. (2001). When arousal influences ad evaluation and valence does not (and vice versa). Journal of Consumer Psychology, 11(1), 43-55.

Gorn, G. J., Chattopadhyay, A., Sengupta, J., \& Tripathi, S. (2004). Waiting for the web: How screen color affects time perception. Journal of Marketing Research, 41(2), 215-225.

Gorn, G. J., Chattopadhyay, A., Yi, T., \& Dahl, D. W. (1997). Effects of color as an executional cue in advertising: They're in the shade. Management Science, 43(10), $1387-1400$

Grinstein, A., Hagtvedt, H., \& Kronrod, A. (2019). Aesthetically (dis)pleasing visuals: A dual pathway to empathy and prosocial behavior. International Journal of Research in Marketing, 36(1), 83-99.

Hagtvedt, H., \& Brasel, S. A. (2017). Color saturation increases perceived product size. Journal of Consumer Research, 44(2), 396-413.

Hayes, A. F. (2013). Introduction to mediation, moderation, and conditional process analysis: A regression-based approach. New York, NY: Guilford Press.

Isen, A. M., \& Levin, P. F. (1972). Effect of feeling good on helping: Cookies and kindness. Journal of Personality and Social Psychology, 21(3), 384-388. 
Isen, A. M., \& Noonberg, A. (1979). The effect of photographs of the handicapped on donation to charity: When a thousand words may be too much. Journal of Applied Social Psychology, 9(5), 426-431.

Jones, D. N., \& Neria, A. I. (2015). The dark triad and dispositional aggression. Personality and Individual Differences, 86, 360-364.

Kareklas, I., Brunel, F. F., \& Coulter, R. A. (2013). Judgment is not color blind: The impact of automatic color preference on product and advertising preferences. Journal of Consumer Psychology, 24, 87-95.

Karp, E. M., \& Karp, H. B. (2001). Color associations of male and female fourth-grade school children. The Journal of Psychology, 122(4), 383-388.

Kim, H., Park, K., \& Schwarz, N. (2010). Will this trip really be exciting? The role of incidental emotions in product evaluation. Journal of Consumer Research, 36(6), 983-991.

Kimchi, R., \& Palmer, S. E. (1982). Form and texture in hierarchically constructed patterns. Journal of Experimental Psychology: Human Perception and Performance, 8(4), 521-535.

Krebs, D. L. (1970). Altruism: An example of the concept and a review of the literature. Psychological Bulletin, 73(4), $258-302$.

Labrecque, L. I., \& Milne, G. R. (2012). Exciting red and competent blue: The importance of color in marketing. Journal of the Academy of Marketing Science, 40(5), 711-727.

Labrecque, L. I., Patrick, V. M., \& Milne, G. R. (2013). The marketers' prismatic palette: A review of color research and future directions. Psychology E' Marketing, 30(2), $187-202$.

Laroche, M., Kim, C., \& Zhou, L. (1996). Brand familiarity and confidence as determinants of purchase intention: An empirical test in a multiple brand context. Journal of Business Research, 37(2), 115-120.

Lee, H., Deng, X., Unnava, H. R., \& Fujita, K. (2014). Monochrome forests and colorful trees: The effect of black-and-white versus color imagery on construal level. Journal of Consumer Research, 41(4), 1015-1032.

Levy, B. I. (1984). Research into the psychological meaning of color. American Journal of Art Therapy, 23(2), 58-62.

Machleit, K. A., Allen, C. T., \& Madden, T. J. (1993). The mature brand and brand interest: An alternative consequence of ad-evoked affect. Journal of Marketing, 57(October), 72-82.

MacKenzie, S. B., Lutz, R. J., \& Belch, G. E. (1986). The role of attitude toward the ad as a mediator of advertising effectiveness: A test of competing explanations. Journal of Marketing Research, 23(2), 130-143.

Mandler, G. (1982). The structure of value: Accounting for taste. In M. S. Clark, \& S. T. Fiske (Eds.), Affect and cognition: The 17th annual Carnegie symposium (pp. 3-36). Hillsdale, NJ: Lawrence Erlbaum Associates.

Manucia, G. K., Baumann, D. J., \& Cialdini, R. B. (1984). Mood influences on helping: Direct effects or side effects? Journal of Personality and Social Psychology, 46(2), 357-364.

McMenamin, B. W., Radue, J., Trask, J., Huskamp, K., Kersten, D., \& Marsolek, C. J. (2013). The diagnosticity of color for emotional objects. Motivation and Emotion, 37(3), 609-622.

Mehta, R., \& Zhu, R. (2009). Blue or red? Exploring the effect of color on cognitive task performances. Science, 323(5918), 1226-1229.

Meier, B. P., D'Agostino, P. R., Elliot, A. J., Maier, M. A., \& Wilkowski, B. M. (2012). Color in context: Psychological context moderates the influence of red on approachand avoidance-motivated behavior. PLoS One, 7(7), e40333.

Meißner, M., Musalem, A., \& Huber, J. (2016). Eye tracking reveals processes that enable conjoint choices to become increasingly efficient with practice. Journal of Marketing Research, 53(1), 1-17.

Meyers-Levy, J., \& Peracchio (1995). Understanding the effects of color: How the correspondence between available and required resources affects attitudes. Journal of Consumer Research, 22(2), 121-138.

Meyvis, T., \& Van Osselaer, S. M. (2018). Increasing the power of your study by increasing the effect size. Journal of Consumer Research, 44(5), 1157-1173.

Moore, R. S., Stammerjohan, C. A., \& Coulter, R. A. (2005). Banner advertiser web site congruity and color effects on attention and attitudes. Journal of Advertising, 34(2), 71-84.

National Center for Charitable Statistics (2017). Quick facts about nonprofits. Retrieved from http://nccs.urban.org/data-statistics/quick-facts-about-nonprofits.

Nielsen Company (2017). The Nielsen total audience report: Q2 2017. Retrieved from http://www.nielsen.com/us/en/insights/reports/2017/the-nielsen-total-a udience-q2-2017.html.

Okon-Singer, H., Tzelgov, J., \& Henik, A. (2007). Distinguishing between automaticity and attention in the processing of emotionally significant stimuli. Emotion, 7(1), $147-157$.

Orquin, J. L., \& Loose, S. M. (2013). Attention and choice: A review on eye movements in decision making. Acta Psychologica, 144(1), 190-206.

Palmer, S. E., Schloss, K. B., Xu, Z., \& Prado-León, L. R. (2013). Music-color associations are mediated by emotion. Proceedings of the National Academy of Sciences, 110 (22), 8836-8841.

Paolacci, G., Chandler, J., \& Ipeirotis, P. G. (2010). Running experiments on Amazon Mechanical Turk. Judgment and Decision making, 5, 411-419.

Pessoa, L., McKenna, M., Gutierrez, E., \& Ungerleider, L. G. (2002). Neural processing of emotional faces requires attention. Proceedings of the National Academy of Sciences, 99(17), 11458-11463.

Pessoa, L., Padmala, S., \& Morland, T. (2005). Fate of unattended fearful faces in the amygdala is determined by both attentional resources and cognitive modulation. Neuroimage, 28(1), 249-255.

Pirlott, A. G., \& MacKinnon, D. P. (2016). Design approaches to experimental mediation. Journal of Experimental Social Psychology, 66, $29-38$.

Pryke, S. R. (2009). Is red an innate or learned signal of aggression and intimidation? Animal Behaviour, 78(2), 393-398.

Scherer, K. R. (1999). Appraisal theory. In T. Dalgleish, \& M. J. Power (Eds.), Handbook of cognition and emotion (pp. 637-663). Chichester: John Wiley.

Schifferstein, H. N., \& Tanudjaja, I. (2004). Visualizing fragrances through colours: The mediating role of emotions. Perception-London, 33(10), $1249-1266$.

Schwarz, N., \& Clore, G. L. (1983). Mood, misattribution, and judgments of well-being: Informative and directive functions of affective states. Journal of Personality and Social Psychology, 45(3), 513-523.

Sheppard, B. H., Hartwick, J., \& Warshaw, P. R. (1988). The theory of reasoned action: A meta-analysis of past research with recommendations for modifications and future research. Journal of Consumer Research, 15(3), 325-343.

Sivik, L., \& Taft, C. (1989). Semantic variables for judging color combinations-An analysis of semantic dimensions. Göteborg Psychological Reports, 19(5), 1-31.

Small, D. A., \& Verrochi, N. M. (2009). The face of need: Facial emotion expression on charity advertisements. Journal of Marketing Research, 46(6), 777-787.

Smith, C. A., \& Ellsworth, P. C. (1985). Patterns of cognitive appraisal in emotion. Journal of Personality and Social Psychology, 48(4), 813-838.

Thornton, B., Kirchner, G., \& Jacobs, J. (1991). Influence of a photograph on a charitable appeal: A picture may be worth a thousand words when it has to speak for itself. Journal of Applied Social Psychology, 21(6), 433-445.

Valdez, P., \& Mehrabian, A. (1994). Effects of color on emotions. Journal of Experimental Psychology, 123(4), 394-409.

Vuilleumier, P., Armony, J. L., Driver, J., \& Dolan, R. J. (2003). Distinct spatial frequency sensitivities for processing faces and emotional expressions. Nature Neuroscience, 6(6), 624-631.

Watson, D., \& Tellegen, A. (1985). Toward a consensual structure of mood. Psychological Bulletin, 98(2), 219-235.

Weyant, J. M. (1978). Effects of mood states, costs, and benefits on helping. Journal of Personality and Social Psychology, 36(1), $1169-1176$.

White, K., \& Peloza, J. (2009). Self-benefit versus other-benefit marketing appeals: Their effectiveness in generating charitable support. Journal of Marketing, 73(4), 109-124. 